\title{
PPM Usaha Mikro Makanan Ringan Kelurahan Karah Kota Surabaya
}

\author{
Iful Novianto ${ }^{1}$, Hendrik Rizqiawan ${ }^{2}$, Andi Iswoyo ${ }^{3}$, Yanuar Fauzuddin ${ }^{4}$ \\ ${ }^{1}$ Universitas Wijaya Putra \\ ${ }^{2}$ Universitas Wijaya Putra \\ ${ }^{3}$ Universitas Wijaya Putra \\ ${ }^{4}$ Universitas Wijaya Putra
}

iful_novianto@yahoo.com, hendrik_rizqiawan@yahoo.com, andi@uwp.ac.id, yanuarfauzuddin@gmail.com

\begin{abstract}
Abstrak
Mitra merupakan pelaku usaha rumahan dengan produk berbagai macam makanan ringan seperti brownies, kue kacang, hingga makanan yang biasa disajikan untuk hari raya atau lebaran. Berlokasi di Kelurahan Karah Kecamatan Jambangan Kota Surabaya persisnya di Jl. Karah 151, mitra menjalankan usahanya seorang diri di tengah keterbatasnnya dan terkadang dibantu suami. Keterbatasan yang dimaksud antara lain kondisi dapur mitra yang cukup kecil dan sempit, hal tersebut yang menjadi alasan mitra menggunakan "Dapoer Sempit" sebagai merek produknya. Selain itu keterbatasan lainnya adalah dari sisi modal, sehingga mitra belum dapat berinvestasi pada peralatan produksi yang lebih layak \& sesuai, dan aspek higienitas juga dinilai kurang diperhatikan.

Tujuan program ini adalah agar mitra memiliki peralatan produksi yang layak, lebih memperhatikan faktor higienitas, ada varian kemasan \& label baru yang lebih menarik, dan mitra dapat memanfaatkan media sosial \& marketplace secara maksimal dalam memasarkan produknya. Program ini berjalan selama dua bulan yaitu pada bulan Juli hingga Agustus 2021, dengan metode pelaksanaan berupa pengadaan barang serta pendampingan personal. Setelah pelaksanan program ini, dengan peralatan produksi yang lebih layak, mitra dapat meningkatkan produktivitasnya, produk mitra terkemas lebih cantik dan menarik, serta jangkauan pemasaran mitra lebih luas.
\end{abstract}

Kata Kunci: Usaha Mikro, Kewirausahaan, Makanan Ringan, Surabaya

\section{PENDAHULUAN}

Tidak ada yang mengetahui secara persis mulai kapan Usaha Mikro Kecil dan Menengah (UMKM) ada di bumi Nusantara atau negara Indonesia. Terlebih, jika diamati berdasarkan aktivitasnya, UMKM adalah bagian yang tidak dapat dilepas atau terpisah dengan kehidupan segala lapisan masyarakat dalam rangka memenuhi dan mencukupi kebutuhannnya, khususnya pada kegiatan ekonomi (Fajar, 2015). Di Indonesia, Usaha Mikro Kecil dan Menengah (UMKM) merupakan salah satu bidang usaha yang memiliki peranan cukup vital dan penting dalam rangka pertumbuhan ekonomi, UMKM juga memiliki andil dan kontribusi dalam penyerapan tenaga kerja (menciptakan lapangan pekerjaan) dan distribusi hasil-hasil pembangunan (Soetjipto, 2020).

Sebagaimana PP 7 tahun 2021, usaha mikro adalah usaha produktif milik orang perorangan dan atau badan usaha perorangan yang memiliki hasil penjualan tahunan sampai dengan paling banyak dua miliar rupiah. Mitra program pemberdayaan masyarakat (PPM) merupakan pengusaha mikro dan sudah menjalankan usahanya selama 4 tahun ini. Usaha tersebut memproduksi dan menjual aneka produk makanan ringan dan berlokasi di Kelurahan Karah Kecamatan Jambangan Kota Surabaya 
persisnya di Jl. Karah 151. Mitra bernama lengkap Ibu Jayanti Nengseh yang memproduksi beraneka makanan ringan dengan berbagai macam varian, mulai dari brownies, kue kacang, hingga makanan yang biasa disajikan untuk hari raya atau lebaran (nastar, putri salju, cookies coklat dan lainnya). Mitra selama ini menjalankan usahanya seorang diri di tengah keterbatasnnya dan terkadang dibantu suami. Keterbatasan yang dimaksud antara lain kondisi dapur mitra cukup kecil dan sempit, hal tersebut yang menjadi alasan mitra menggunakan "Dapoer Sempit" sebagai merek produknya. Selain itu keterbatasan lainnya adalah dari sisi modal, sehingga mitra belum dapat berinvestasi pada peralatan dan perlengkapan produksi yang lebih layak dan sesuai. Mitra memproduksi produknya ketika ada pesanan dari pelanggan, diantara berbagai macam produknya, brownis dan kue kacang merupakan produk mitra yang ajeg dipesan oleh pelanggan, karena selain produk tersebut pesanan banyak ketika momen-momen tertentu saja, seperti ketika memperingati hari raya. Selama pandemi omzet yang didapatkan berkurang walau tidak siginifikan, yaitu sekitar 1,3 juta rupiah per bulan, dan ketika di bulan Ramadhan omzet yang dihasilkan bisa 2 hingga 3 kali lipat. Angka tersebut dirasa mitra cukup membantu untuk menutupi kebutuhan sehari-hari dan tentunya dapat menambah masukkan selain mengandalkan pendapatan suami mitra yang bekerja sebagai supir. Harga yang dibandrol oleh mitra juga dapat dinilai sesuai dengan harga pasaran atau harga kompetitor lainnya, seperti brownies yang mitra jual dengan harga Rp. 11.000 per pack kemasan kecil dan Rp. 50.000 per pack kemasan besar, harga yang sama pada produk mitra yaitu kue kacang dalam kemasan toples, kemudian nastar, dan putri salju yang memiliki harga masing-masing sebesar Rp. 70.000 dan Rp. 60.000 per toples.

Namun ada beberapa permasalahan yang dihadapi oleh mitra selama menjalankan usahanya. Permasalahan mitra antara lain pada aspek produksi, mitra kurang memperhatikan aspek higienitas pangan ketika dalam proses produksi, dan sebagaimana disebutkan sebelumnya, peralatan produksi mitra yang berupa oven kurang efektif dan aman, karena dibutuhkan tambahan arang dibagian dalam proses pemanggangan agar kue matang dan kering merata. Lalu pada aspek pengemasan, ada salah satu varian produk yang mitra produksi (brownies panggang) dikemas menggunakan kemasan yang kurang tepat dan kurang menarik dan juga label produk mitra masih berbahan kertas yang diprint, sehingga rentan luntur jika terkena air. Kemudian pada aspek pemasaran, mitra sejauh ini menjual produknya hanya berdasarkan pesanan dari orang-orang yang dikenal saja. Mitra belum memanfaatkan media sosial Instagram secara maksimal pada aktivitas promosi. Mitra juga belum menggunakan media marketplace yang memungkinkan untuk digunakan pada aktivitas promosi.

Dari paparan di atas dapat dirumuskan tujuan dari program ini antara lain 1) Mitra memiliki peralatan produksi yang layak dan lebih memperhatikan faktor higienitas, 2) Ada penambahan varian kemasan \& label baru yang lebih menarik, 3) Mitra dapat memanfaatkan media sosial \& marketplace secara maksimal dalam memasarkan produknya.

\section{METODE}

Pelaksanaan program pemberdayaan masyarakat (PPM) ini berjalan selama dua bulan yaitu pada bulan Juli hingga Agustus 2021. Selain melibatkan 4 Dosen Universitas Wijaya Putra yang terdiri dari Iful Novianto, SH., MM., Hendrik Rizqiawan, SE., MM., Andi Iswoyo, SE., MM. \& Yanuar Fauzuddin, SE., MM. juga mengikutsertakan 2 orang mahasiswa Universitas Wijaya Putra yaitu Indra Kurniawan (NPM. 17012150) dan Vicky Nurcahyo (NPM. 17012126).

Metode pelaksanaan yang telah dilakukan merupakan program pendampingan dengan pemberian solusi berdasarkan masalah-masalah yang mitra hadapi dengan rincian sebagai berikut: 1) Pada masalah aspek produksi, metode pelaksanaannya antara lain pengadaan perlengkapan higienitas dalam pengelolaan pangan, pendampingan cara penggunaan dan perawatan perlengkapan higienitas pangan tersebut, kemudian pengadaan peralatan produksi berupa oven yang memiliki api atas dan bawah (2 sisi), pendampingan 
cara penggunaan dan perawatannya dan melakukan evaluasi setiap di akhir pertemuan pendampingan pada aspek produksi.; 2) Pada masalah aspek pengemasan, rincian metode pelaksanaanya ialah pengadaan kemasan yang lebih tepat dan lebih menarik pada salah satu varian produk mitra yang berupa brownies panggang, kemudian pengadaan label untuk produk mitra dengan bahan dasar sticker agar lebih tahan/tidak luntur jika terkena air, serta melakukan evaluasi setiap di akhir pertemuan pendampingan pada aspek pengemasan.; 3) Pada masalah aspek pemasaran, metode pelaksanaan yang dilakukan diantaranya pendampingan promosi menggunakan media sosial Instagram melalui promosi berbayar, lalu pendampingan promosi pada marketplace OLX, dan tentunya melakukan evaluasi setiap di akhir pertemuan pendampingan pada aspek pemasaran.

\section{HASIL DAN PEMBAHASAN}

Program pemberdayaan masyarakat (PPM) ini dilaksanakan di kediaman mitra yang berlokasi di Kelurahan Karah Kecamatan Jambangan Kota Surabaya persisnya di Jl. Karah 151. Dalam pelaksanaan program, mitra terkadang didampingi suami khususnya dalam pendampingan aspek produksi.

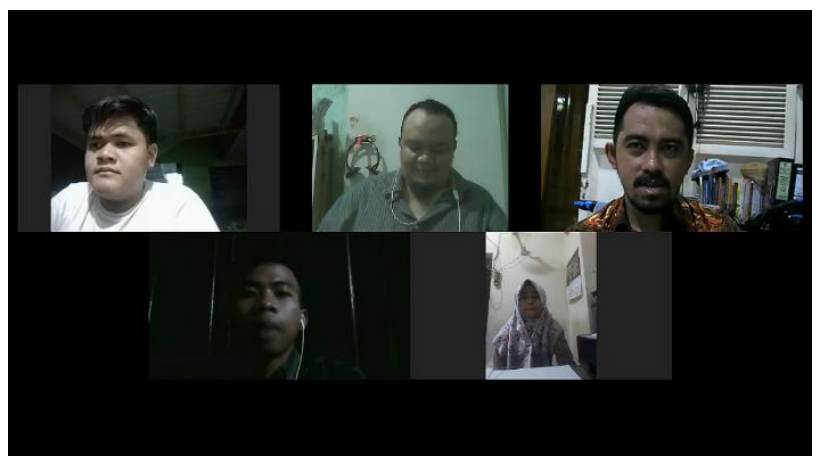

Gambar 1. Persiapan dan koordinasi tim PPM dengan mitra menggunakan Aplikasi Zoom

\section{1 Pendampingan Aspek Produksi}

Selama ini mitra dinilai kurang memperhatikan faktor higienitas atau kebersihan dalam melakukan proses produksi, hal tersebut terlihat dengan tidak adanya perlengkapan higienitas seperti celemek, hair cap dan sarung tangan. Oleh karena itu, tim melakukan pengadaan perlengkapan higienitas dan memberikan pendampingan cara penggunaan dan perawatannya agar proses produksi yang dilakukan mitra lebih terjamin keamanan pangan atau higienitasnya. Faktor higienitas pada proses produksi atau pengolahan makanan memiliki pengaruh terhadap kualitas makanan (produk) yang dihasilkan (Auliya \& Aprilia, 2016).

Oven yang mitra gunakan dalam memproduksi produknya juga kurang efektif dan aman. Maka tim memprioritaskan pengadaan peralatan produksi berupa oven yang memiliki api atas dan bawah (2 sisi) dan langsung tersambung dengan regulator LPG. Tim juga mendampingi mitra dalam penggunaan oven tersebut beserta cara perawatannya. Dengan adanya oven tersebut, produktivitas mitra meningkat dan dapat mengurangi waktu produksi (terjadi efisiensi produksi).

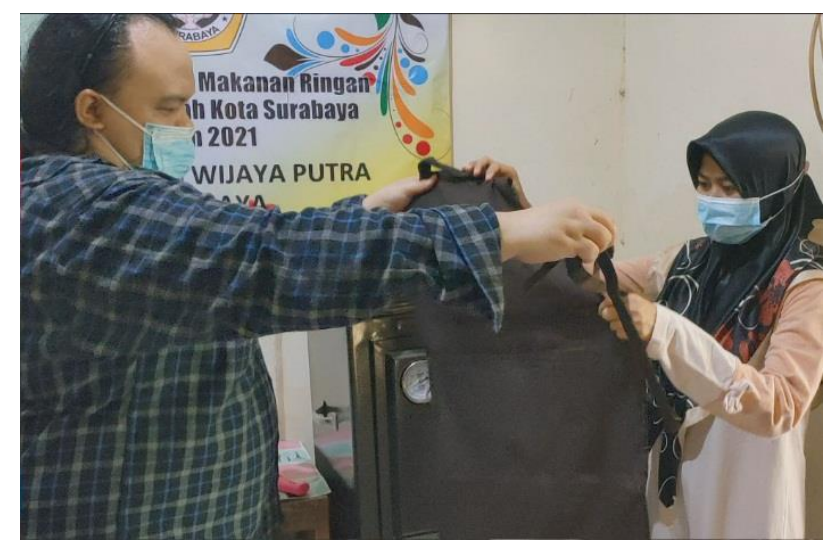

Gambar 2. Serah terima perlengkapan higienitas berupa celemek kepada mitra 


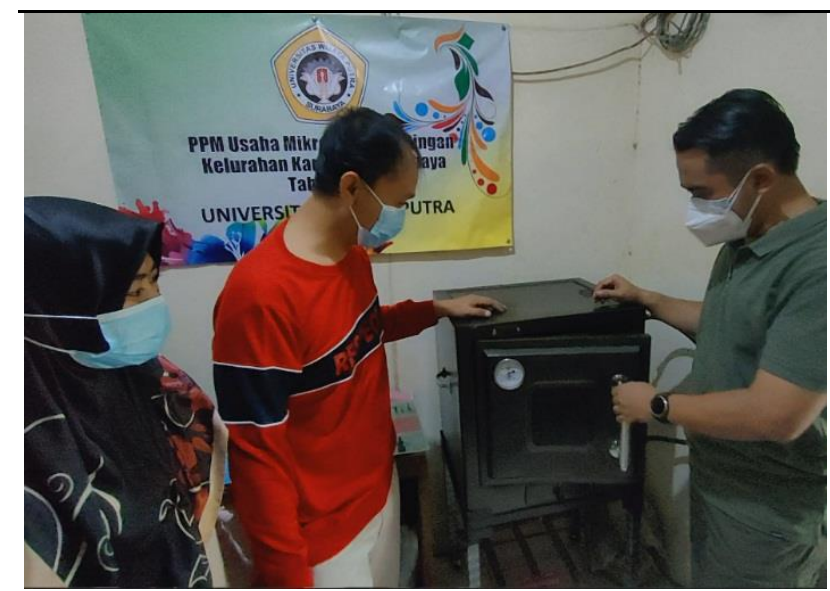

Gambar 3. Serah terima peralatan produksi berupa oven yang memiliki api atas dan bawah (2 sisi) beserta cara penggunaan dan perawatannya.

\section{2 Pendampingan Aspek Pengemasan}

Sebelum terlibat dengan program ini, mitra menggunakan kemasan yang cenderung standar untuk mengemas produknya. Mulai dari kemasan plastik hingga yang terbuat dari dos namun polos dan kurang menarik. Label yang mitra gunakan juga hasil cetak menggunakan print rumahan sehingga mudah luntur dan tidak bverwarna cerah. Tim memberikan solusi berupa kemasan yang lebih elegen, khususnya pada produk mitra yang berupa brownies panggang. Dan terbukti, para pelanggan mitra menyebut jika kemasan baru tersebut lebih cantik dan menarik. Kemasan merupakan salah satu dari sekian faktor yang memilikit pengaruh terhadap minat beli customer atau konsumen (Mufreni, 2016). Untuk label juga diarahkan tempat cetak label dengan harga terjangkau dan kualitas yang baik. Tim sebelumnya memberikan contoh hasil cetak label dari percetakan tersebut dan mitra antusias melihat hasil cetak labelnya.

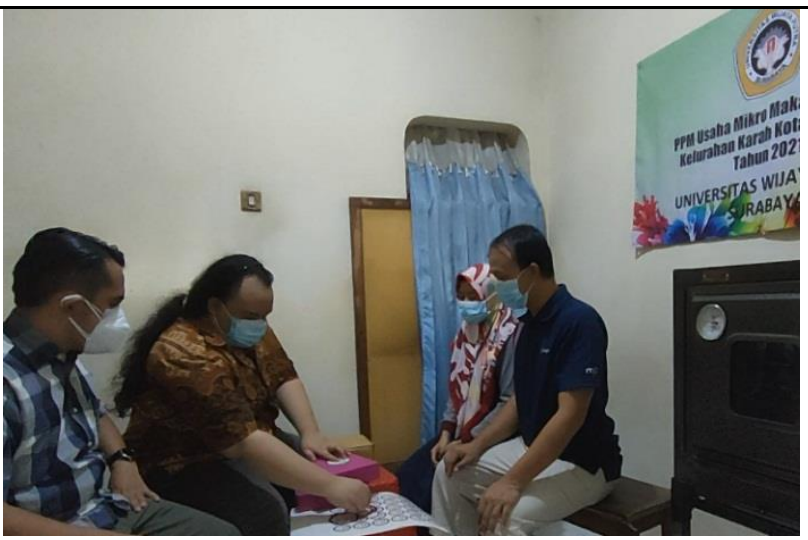

Gambar 4. Pengenalan kemasan baru dan label dengan hasil cetak yang lebih berkualitas.

\section{3 Pendampingan Aspek Pemasaran}

Pada aspek pemasaran, tim memberikan pelatihan dan pendampingan terkait pemanfaatan media sosial dan marketplace untuk memperluas pemasaran dan meningkatkan penjualan mitra. Media sosial yang digunakan yaitu Instagram. Tim mendampingi mitra melakukan promosi berbayar Instagram dan memberikan contoh UMKM mana saja yang cukup terbantu Instagram dalam rangka kegiatan pemasaran khususnya pada aktivitas promosi. Media sosial seperti Facebook dan Instagram dapat digunakan sebagai salah satu metode dalam melakukan promosi yang tepat (Salim et al., 2020). Dengan menggunakan layanan promosi berbayar pada Instagram, memberikan dampak dengan semakin banyaknya masyarakat yang mengenal produk yang dipromosikan. Jumlah like dan kunjungan akun Instagram meningkat dari sebelum menggunakan layanan tersebut (Rizqiawan, et al., 2021). Hal tersebut juga terjadi pada Akun Instagram mitra yang bernama "dapoer.sempit" dimana sebelumnya jumlah like dapat dihitung jari, namun setelah dipromosikan menggunakan promosi berbayar Instagram terjadi peningkatan like yang cukup signifikan (puluhan like) dan bahkan mulai banyak direct message yang dikirimkan oleh calon customer menanyakan produk mitra. 


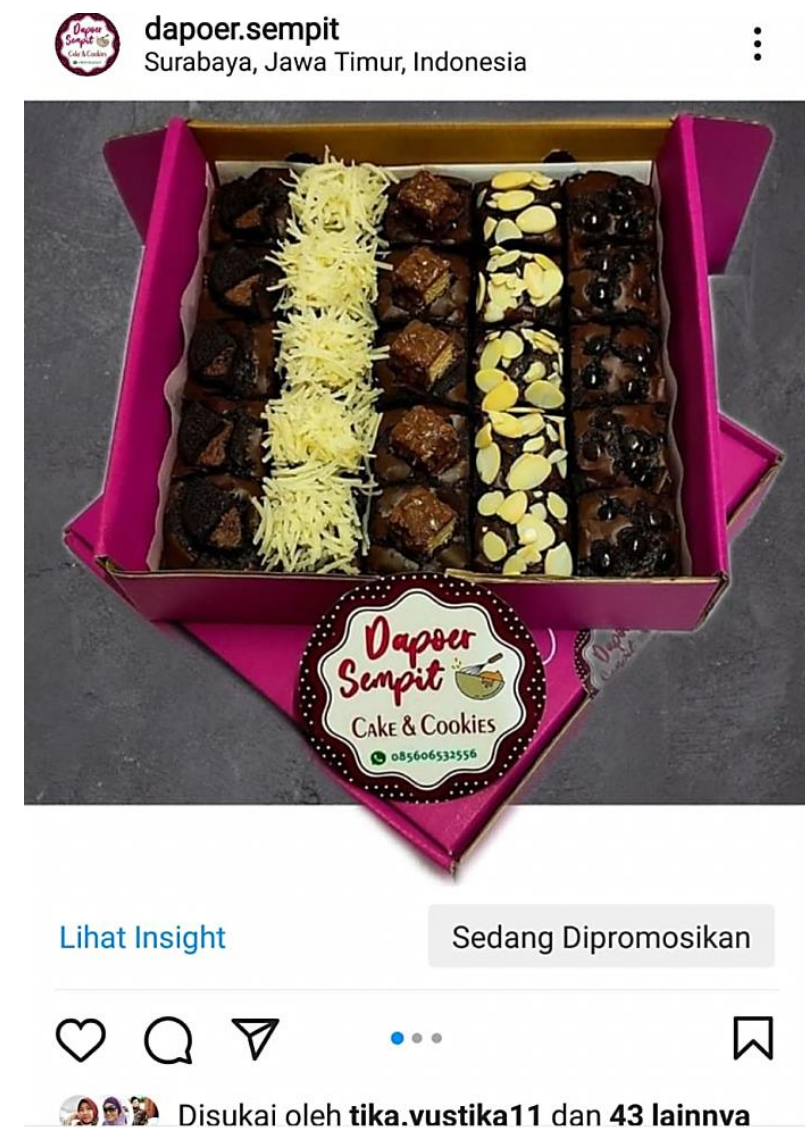

Gambar 5. Tampilan promosi berbayar Instagram pada akun Instagram mitra

Adapun marketplace yang digunakan ialah

OLX. Marketplace tersebut dipilih karena memperkankan mitra menampilkan kontak WA yang dapat dihubungi ketika memasarkan produknya. Media marketplace dapat membantu dalam peningkatan pendapatan para pelaku Usaha Kecil dan Menengah (UMKM) baik secara langsung ataupun tidak langsung (Mutianingrum, 2019).

\section{KESIMPULAN}

Pelaksanaan program pemberdayaan masyarakat (PPM) ini berjalan sesuai rencana walaupun dalam kondisi pandemi. Tentunya dalam pelaksanaan program, tim dan mitra tetap mematuhi prokes dengan baik, seperti penggunaan masker dan menyediakan handsanitizer yang cukup. Mitra merasakan kemanfaatan dari setiap program yang diberikan.

Dengan adanya peralatan produksi yang lebih layak yang berupa oven yang memiliki api atas dan bawah (2 sisi) dan langsung tersambung dengan regulator LPG, mitra mampu meningkatkan produktivitasnya dan waktu produksi juga dapat berkurang. Produk mitra juga sudah terkemas lebih cantik dan menarik. Dengan adanya pendampingan aspek pemasaran, jangkauan pemasaran mitra lebih luas dan tentunya berimbas kepada pengingkatan penjualan.

\section{UCAPAN TERIMAKASIH}

Terima kasih yang sebesar-besarnya disampaikan kepada:

1. Rektor Universitas Wijaya Putra, Bapak Dr. Budi Endarto, SH., M.Hum.;

2. LPPM Universitas Wijaya Putra;

3. Dekan Fakultas Ekonomi dan Bisnis (FEB) Universitas Wijaya Putra Surabaya, Ibu Dr. Soenarmi, SE., MM.;

4. Kaprodi Manajemen Fakultas Ekonomi dan Bisnis (FEB) Universitas Wijaya Putra Surabaya, Ibu Dwi Lesno Panglipursari, SE., MM.

5. Dan segenap pihak lain yang tidak dapat disebutkan.

\section{REFERENSI}

Auliya, A., \& Aprilia, D. N. (2016). Pengaruh Hygiene Pengolahan Makanan Terhadap Kualitas Makanan di Hotel Aston Rasuna Jakarta. Hospitality Dan Pariwisata. 2(2): 216-227.

Fajar, Mukti. (2015). UMKM dan Globalisasi Ekonomi. Yogyakarta: LP3M Universitas Muhammadiyah Yogyakarta.

Mufreni, A. N. (2016). Pengaruh Desain Produk, Bentuk Kemasan dan Bahan Kemasan terhadap Minat Beli Konsumen (Studi Kasus Teh Hijau Serbuk Tocha). Ekonomi Manajemen. 2(November): 48-54.

Mutianingrum, R. A. (2019). Analisis Faktor-Faktor yang Mempengaruhi Penjualan Via 
Platform Online Marketplace dan Pengaruhnya terhadap Pendapatan Pelaku UKM (Studi pada Pelaku UKM di Kota Malang). Jurnal Ilmiah Mahasiswa FEB Universitas Brawijaya. 7(2).

Pemerintah Republik Indonesia (2021). Peraturan Pemerintah Republik Indonesia Nomor 7 Tahun 2021 tentang Kemudahan, Pelindungan, dan Pemberdayaan Koperasi Dan Usaha Mikro, Kecil, dan Menengah.

Rizqiawan, H., Novianto, I. \& Subaderi, S. (2021). Model of Application of Technology to Increase Income in Micro Business Clover Stick in
The Face of Covid19 Pandemic Era. Procedia of Social Sciences and Humanities, 1(2021): Proceedings of the 2nd International Conference On Intelectuals Global Responsibility (ICIGR 2020). Salim, E., Hendri, H., \& Robianto, R. (2020). Strategi Pengembangan Usaha dan Peningkatan Kinerja dalam Menghadapi Era Digital pada UMKM Café Tirtasari Kota Padang. JMM (Jurnal Masyarakat Mandiri). 4(1): 10-17.

Soetjipto, Noer. (2020). Ketahanan UMKM

Jawa Timur Melintasi Pandemi COVID-19. Yogyakarta: Penerbit K-Media. 